\title{
Proposta de Tratamento Fisioterapêutico para Crianças Portadoras de Paralisia Cerebral Espástica, com Ênfase nas Alterações Musculoesqueléticas
}

\author{
Ana Paula Marega Cargnin* \\ Carla Mazzitelli**
}

\section{RESUMO}

A paralisia cerebral ou encefalopatia crônica não-progressiva é o termo usado para designar um grupo de desordens sensoriomotoras, resultante de lesão cerebral nos primeiros estágios do desenvolvimento. Essas desordens caracterizam-se pela falta de controle sobre os movimentos, por modificações adaptativas do comprimento muscular, podendo, em alguns casos, resultar em deformidades ósseas. Este trabalho visa à elaboração de uma proposta de tratamento fisioterapêutico com ênfase na abordagem das principais alterações musculoesqueléticas das crianças com paralisia cerebral espástica tetraparética, diparética e hemiparética. Os resultados deste estudo detalham exercícios para mobilidade, estabilidade articular, força e treino funcional, para que essas crianças obtenham independência e qualidade de vida.

Unitermos: Paralisia cerebral, tratamento fisioterapêutico, deformidades musculoesqueléticas.

\section{Introdução}

A paralisia cerebral (PC), também denominada encefalopatia crônica não-progressiva da infância, é conseqüência de uma lesão estática, ocorrida no período pré, peri ou pós-natal que afeta o sistema nervoso central em fase de maturação estrutural e funcional ${ }^{17}$. É uma disfunção predominantemente sensoriomotora, envolvendo distúrbios no tônus muscular, na postura e na movimentação voluntária. Esses distúrbios caracterizam-se pela falta de controle sobre os movimentos, por modificações adaptativas do comprimento muscular, resultando, em alguns casos, em deformidades ósseas ${ }^{21}$.

O comprometimento neuromotor dessa doença pode envolver partes distintas do corpo, resultando em classificações topográficas específicas (tetraplegia, hemiplegia e diplegia), sendo a forma espástica a mais encontrada em crianças com paralisia cerebral. Outro tipo de classificação é a baseada nas alterações clínicas do tônus muscular e no tipo de desordem do movimento (espástico, atetóide, atáxico e misto) ${ }^{19}$.
A espasticidade pode ser definida como "aumento na tensão do músculo quando ele é passivamente alongado, a qual é causada por um exagero do reflexo de estiramento muscular" ${ }^{22}$. A espasticidade pode afetar de maneira adversa o desenvolvimento motor, levando a posturas e padrões de movimentos anormais, deformidades musculoesqueléticas e atrasos na aquisição das habilidades motoras, nos quais incluem o sentar-se, o engatinhar, o ficar em pé e o caminhar ${ }^{13}$.

A criança com paralisia cerebral espástica comumente evolui com alterações musculoesqueléticas secundárias à alteração do tônus muscular e conseqüentemente dificuldade para o movimento voluntário.

O tratamento da criança com paralisia cerebral deve ser realizado por uma equipe multidisciplinar composta por médicos de várias especialidades, bem como por terapeuta ocupacional, fisioterapeuta, fonoaudiólogo, assistente social, educador e psicólogo $\mathrm{o}^{3,10,11,18}$.

Segundo Campbell ${ }^{8}$, com um tratamento apropriado, é possível diminuir as deficiências funcionais

* Pós-graduanda em Fisioterapia Neurológica (Umesp). Fisioterapeuta Formada pela Unisul.

** Mestre em Neurociências e Comportamento da Universidade de São Paulo (USP). Professora de Fisioterapia da Umesp. Fisioterapeuta formada pela USP. 
em muitas crianças, sendo a meta de tratamento nos casos de paralisia cerebral o aumento, tanto quanto possível, das habilidades do paciente e a diminuição das suas deficiências.

O ortopedista e o fisioterapeuta são responsáveis em prevenir e corrigir as deformidades dos membros superiores e inferiores, contribuindo para que o paciente seja o mais independente possível nas suas atividades da vida diária (AVD) e na sua locomoção ${ }^{10}$.

Não existe apenas um método ou um sistema de tratamento para a criança com paralisia cerebral. Cada paciente tem sua necessidade individual, e o tratamento depende da avaliação do paciente.

$\mathrm{O}$ tratamento dessas afecções pode compreender fisioterapia, uso de recursos auxiliares (por exemplo a órtese) e cirurgia corretiva em alguns casos.

O tratamento fisioterapêutico é bastante abrangente, devendo sempre considerar as alterações funcionais secundárias ao comprometimento neurológico e as biomecânicas. Assim, devemos considerar o alongamento muscular, a estabilidade articular e a força associados ao controle central para a realização das atividades funcionais diárias, que envolvem a capacidade para adoção e manutenção das diferentes posturas, assim como para a realização de seus movimentos.

\section{Objetivo}

O objetivo deste trabalho é elaborar uma proposta de tratamento fisioterapêutico para crianças portadoras de paralisia cerebral espástica com ênfase nas alterações musculoesqueléticas, a fim de prevenir e corrigir deformidades, para que a criança tenha maior capacidade de realizar atos indispensáveis para a vida cotidiana, com maior eficácia, obtendo, assim, melhor qualidade de vida e independência.

\section{Metodologia}

O presente trabalho trata-se de uma revisão bibliográfica, compreendendo artigos e livros científicos, desde 1973 a 2001. Os artigos foram pesquisados em banco de dados, como o Medline e o Pubmed. Nas bibliotecas da Umesp e BIREME, foram pesquisados livros científicos relacionados à paralisia cerebral com ênfase nas alterações ortopédicas.

O estudo realizado por Amaral et al. (conferir artigo da página 29 , nesta edição) em 24 crianças, incluindo ambos os sexos, com paralisia cerebral espástica tetraparética, diparética e hemiparética, atendida na Clínica-Escola de Fisioterapia da
Universidade Metodista de São Paulo, teve como objetivo verificar a incidência e os tipos de deformidades ortopédicas presentes nessas crianças. Foi observado que as principais alterações ortopédicas nos pacientes tetraparéticos foram o pé equiino, a rotação interna de quadril e ombro e a flexão de cotovelo e punho. Nos pacientes diparéticos foram observados pés planos e valgos, pés eqüinos, joelho valgo, flexão de joelho e quadril. Já nos pacientes hemiparéticos, as alterações mais encontradas foram pé plano e valgo, joelho valgo e flexão de joelho. Com base nas principais alterações observadas nesse estudo e na literatura pesquisada como conduta fisioterapêutica para pacientes com paralisia cerebral, elaboramos uma proposta de intervenção fisioterapêutica.

\section{Resultados}

\section{Membros inferiores}

\section{Pé e tornozelo}

\section{Pé eqüino}

A deformidade em pé eqüino em crianças com paralisia cerebral é uma das manifestações motoras mais comuns ${ }^{15}$.

Como descrito por vários autores, o pé eqüino está, na maioria dos casos, associado ao varismo de retropé, adução e supinação de antepé e acentuação do cavo plantar. Por isso, é comumente denominado de deformidade em pé eqüino varo ${ }^{6,12,18,21}$.

A deformidade em pé eqüino pode resultar em problemas na articulação do joelho, na marcha, no equilíbrio e na propriocepção ${ }^{15}$.

$\mathrm{O}$ tratamento deve ser realizado primeiramente de maneira conservadora, sendo iniciado o mais precoce possível ${ }^{12,18}$. As estruturas mecânicas (tanto as ósseas quanto os tecidos moles) se desenvolverão de acordo com as solicitações que forem submetidas. Se o pé eqüino não for tratado, a estrutura óssea estará sujeita a solicitações anormais e os tecidos moles apresentarão novas alterações de caráter adaptativo, agravando a deformidade ${ }^{21}$.

A mobilização do pé eqüino deve ser realizada pelo fisioterapeuta que disponha de conhecimentos detalhados sobre a anatomia e a mobilidade do pé12.

Há vários procedimentos que podem ser realizados, tais como:

Exercício 1 (mobilização passiva): com uma das mãos o fisioterapeuta segura o calcâneo e as extremidades distais da tíbia e da fíbula. Dessa maneira, o fisioterapeuta é capaz de proteger as 
epífases da fíbula e da tíbia contra a ação das forças tangenciais e de fixar a metade posterior do pé, enquanto a outra mão mobiliza a porção anterior do pé, corrigindo sua posição de adução e plantiflexão.

Depois de se obter um certo grau de correção, o tendão de calcâneo poderá ser alongado de maneira mais eficaz. Uma das mãos do fisioterapeuta segura o pé, enquanto o calcanhar é tracionado para baixo, para alongar os músculos flexores da planta do pé ${ }^{21}$.

O paciente deve estar em decúbito dorsal e os joelhos mantidos em flexão, para evitar a distensão do ligamento interno do joelho ${ }^{21}$.

Exercício 2 (alongamento do músculo tibial posterior): com o paciente em decúbito dorsal, o terapeuta segura a superfície plantar do pé com uma das mãos, com a outra a face distal da tíbia e fíbula, trazendo o pé para dorsiflexão e eversão, alongando, assim, o tibial posterior ${ }^{14}$.

Exercício 3 (posição ortostática): após a mobilização passiva, o paciente pode ser posicionado em ortostatismo, mesmo nos casos de tetraplegia, com o auxílio de uma bola terapêutica. $O$ fisioterapeuta permanece atrás do paciente corrigindo a posição do pé.

Exercício 4: estimular o paciente a fazer a dorsiflexão ativa do pé, e, se possível, resistida.

Pode-se também fazer uso de órtese, para que os músculos permaneçam alongados.

\section{Pé plano}

O pé plano, vulgarmente chamado de "pé chato", é uma deformidade que provoca um enorme desperdício de energia ${ }^{4}$.

Até os três anos de idade, o pé da criança têm maior grau de mobilidade que o pé do adulto, em consequiência da maior elasticidade ligamentar peculiar do início da vida ${ }^{4}$. Esse fato, aliado ao alargamento da base de sustentação da criança no início da marcha, facilita a queda do calcâneo em valgo $\mathrm{o}^{3,4,12,16,18}$.

O pé plano na paralisia cerebral ocorre por encurtamento do tendão de aquiles ${ }^{9}$ ou por uma diminuição da descarga de peso, quando, por exemplo, a criança demora para andar, o que, geralmente, está associado ao valgismo do pé e do joelho ${ }^{1}$.

Durante muito tempo, o tratamento para os pés planos consistia em aumentar o arco interno no sapato, mas esse método nunca foi satisfatório ${ }^{20}$. De acordo com muitos autores, o tratamento do pé plano deve ser realizado de modo conservador ${ }^{1,4,12,18,12}$. Em crianças com paralisia cerebral espástica, o tratamento fisioterapêutico do pé plano deve visar a formação do arco. Em crianças que deambulam, como as hemiparéticas e as diparéticas, o tratamento pode ser realizado ativamente:

Exercício 1: estimular a criança a andar descalça em diferentes tipos de solo, como areia e grama, proporciona aos pés maior mobilidade, além de servir como estímulo proprioceptivo.

Exercício 2: fazer com que o paciente caminhe em cama elástica, estimulando a propriocepção e facilitando a formação do arco plantar.

Em crianças que não deambulam, o tratamento pode ser realizado passivamente:

Exercício 3: com o paciente em decúbito ventral em uma bola terapêutica, o terapeuta posiciona-se atrás do paciente, fazendo com que ele apóie as pontas dos pés no chão, passando para o apoio total e, em seguida, para o apoio nos calcanhares.

Exercício 4: com o paciente sentado no feijão (com o feijão entre suas pernas), fazer com que a criança apóie os pés em inversão no chão.

Exercício 5: se o paciente não possui controle de tronco e cervical, como no caso da maioria das crianças tetraparéticas, uma forma é posicionar o paciente sentado no chão ou no tablado, com o terapeuta sentado atrás estimulando a propriocepção do pé da criança com diferentes texturas, como bolinha ou esponja, para a formação do arco plantar.

Exercício 6: com o paciente sentado no chão, o terapeuta senta-se atrás dele, estimulando com as mãos o pé da criança, fazendo contração da musculatura intrínseca do pé.

\section{Quadril}

As deformidades mais comuns do quadril na paralisia cerebral espástica são adução, flexão e rotação medial, isoladas ou combinadas entre si, e o tipo de deformidade depende do grau e da distribuição do envolvimento ${ }^{5,22}$.

\section{Flexão-Adução}

Os músculos iliopsoas, sartório, retofemural, gracilis e adutor médio são, pela ordem, os flexores do quadril mais importantes. Esses músculos são sinérgicos, porém colaboram diferentemente na flexão, dependendo da posição articular ${ }^{11}$.

A deformidade em flexão-adução surge inicialmente como conseqüência de um desequilíbrio entre agonistas e antagonistas, agravando-se progressivamente. Essas alterações musculares em pacientes que não deambulam determinam o aparecimento de deformidades ósseas, como o valgismo e a anteversão exagerada do colo do fêmur, podendo levar à luxação de quadril ${ }^{10}$. 
A flexão do quadril também pode estar associada à flexão dos joelhos, produzindo a posição agachada ou em crouch, que é agravada quando existe fraqueza de sóleo por sua insuficiência ou por alongamento excessivo do tendão de Aquiles ${ }^{10,11}$.

\section{Rotação interna}

A deformidade em rotação interna do quadril pode ser causada por espasticidade dos músculos que rodam medialmente o quadril, que são o glúteo mínimo e a porção anterior do glúteo médio, o tensor da fáscia, os isquiotibiais mediais e a porção anterior dos adutores dos quadris ${ }^{22}$. A rotação interna também pode ser causada pelo valgismo e pela anteversão do colo do fêmur, em virtude da flexão e da adução do quadril ${ }^{11}$.

Exercício 1 (extensão de quadril): com o paciente em decúbito ventral na bola terapêutica, o terapeuta apóia e segura a face anterior do fêmur do paciente distalmente e, com a outra, estabiliza as nádegas do paciente para prevenir os movimentos da pelve, alongando, assim, o iliopsoas e estendendo o quadril.

Exercício 2 (extensão de quadril): o paciente é posicionado em decúbito lateral, com o membro de baixo em flexão, facilitando a estabilização de sua postura. $\mathrm{O}$ terapeuta estabiliza a pelve com uma das mãos na crista ilíaca e com a outra mão distalmente na face medial do fêmur traz o quadril para extensão, alongando os músculos flexores do quadril ${ }^{14}$.

Exercício 3 (abdução de quadril): o paciente é posicionado em decúbito dorsal, o terapeuta com uma das mãos apóia distalmente a coxa e, em seguida, com a outra mão, apóia o outro membro. Abduzir o quadril o máximo possível para alongar os adutores ${ }^{14}$.

Exercício 4 (abdução do quadril): com o paciente sentado com as pernas abduzidas (cavalinho) no feijão, com os pés apoiados no chão, associa-se a isso a rotação externa do quadril.

Exercício 5 (posição ajoelhada e semi-ajoelhada): com o paciente na posição ajoelhada ou semiajoelhada, transfere-se o peso nos membros inferiores, fortalecendo e melhorando a estabilidade do quadril. Se for preciso, o terapeuta pode dar suporte ao paciente, ou utilizar uma bola terapêutica na frente da criança. Na posição semi-ajoelhada, o terapeuta deve cuidar para que não ocorra a adução do quadril, ou ainda, quando possível, estimular a abdução ativa/ resistida da perna que está na frente.

Exercício 6 (descendo escadas): em pacientes hemiparéticos, uma boa alternativa é usar uma escada como recurso terapêutico. O terapeuta fica na frente do paciente, fazendo com que a criança desça a escada com a perna sadia, transferindo o peso para a perna hemiplégica. A criança deverá fazer a transferência de peso para o hemicorpo afetado, além da extensão do quadril. Cuidar para que o joelho permaneça alinhado, impedindo a ocorrência de hiperextensão.

Exercício 7 (subir escadas): fazer o paciente subir escadas, fortalecendo a musculatura extensora do quadril e do joelho. Cuidar para que não ocorra hiperextensão de joelho.

Exercício 8 (mobilidade do quadril): com o paciente sentado na beira de um tablado, estando com os pés sem apoio, o terapeuta à frente do paciente, com as mãos envolvendo a parte lateral do quadril, segura a crista ilíaca anterior e posterior, fazendo a anteversão e retroversão do quadril.

Exercício 9 (mobilidade de quadril): com o paciente sentado em uma bola ou em um banquinho, com os pés apoiados, o terapeuta mostra um brinquedo acima da criança, pedindo a ela que o pegue. A criança, então, terá de estender o braço e o tronco, realizando a anteversão do quadril.

Exercício 10 (ponte): estimular a criança a fazer a posição de ponte e pedir a ela que tire as nádegas do chão para fortalecer, assim, a musculatura extensora do quadril.

\section{Joelho}

Durante a marcha, o joelho deve ter uma ampla mobilidade na fase de apoio. Deve também trabalhar sinergicamente com os movimentos de tronco, quadril e tornozelos. Tal situação não acontece adequadamente na paralisia cerebral e, com grande freqüência, ele fica muito rígido com flexão, proporcionando a marcha com o joelho rígido ou a marcha em tríplice flexão ${ }^{4,11}$.

\section{Flexão do joelho}

A deformidade em flexão de joelho freqüentemente está presente na paralisia cerebral, sendo causada para compensar uma deformidade de pé eqüino e deformidade em flexão de quadril, por espasticidade dos flexores de joelho, principalmente os isquiotibiais, ou funcional, para mudar o centro de gravidade e alcançar o equilíbrio ${ }^{4,11,22}$.

Essa deformidade pode ser dinâmica ou fixa. A deformidade dinâmica só aparece quando a criança fica em pé ou anda; se não for tratada, acaba por se transformar em fixa. Tanto em uma quanto em outra coexiste encurtamento dos flexores de joelho, e, quanto maior for o encurtamento dos flexores, maior será a tendência para a fixação da deformidade ${ }^{4}$. 


\section{Joelho valgo}

O joelho valgo caracteriza-se por uma angulação com desvio medial, no qual os côndilos femurais tocamse entre si e os maléolos encontram-se afastados ${ }^{12,23}$.

A maioria das crianças normais de dois a cinco anos de idade apresenta certo grau de joelho valgo, muitas vezes em combinação com os pés planos. Isso por causa da mudança na distribuição do peso corporal

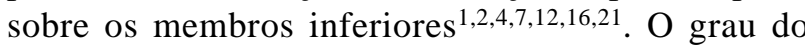
joelho valgo tende a regredir à medida que a criança cresce, embora seja normal um pequeno grau de valgismo do joelho, em virtude das relações entre o fêmur e a tíbia ${ }^{21}$.

Na paralisia cerebral, o valgismo do joelho geralmente está associado à rotação interna do quadril, pé plano valgo e flexão do joelho ${ }^{4}$.

Exercício 1 (extensão do joelho): o paciente é posicionado em decúbito ventral na bola terapêutica. O terapeuta estabiliza o quadril colocando uma das mãos ou antebraço na coxa do paciente e, com a outra mão, segura distalmente a tíbia. Aplica, assim, força na face posterior da tíbia, estendendo o joelho e alongando os flexores.

Exercício 2 (extensão do joelho): com o paciente em decúbito dorsal, apoiar o membro a ser alongado em um dos braços ou mão, estabilizar o membro oposto na face anterior da coxa com a outra mão, para flexionar o quadril e estender o joelho, alongando os isquiotibiais.

Exercício 3 (sentar e levantar): com o paciente sentado em um banquinho, estimulá-lo a levantar para pegar um brinquedo e em seguida a sentar, fortalecendo o quadríceps. Cuidar para manter o alinhamento dos joelhos.

Exercício 4 (subir escadas): fazer com que o paciente suba escadas para fortalecer a musculatura extensora do quadril e do joelho.

\section{Membros superiores}

A postura típica do membro superior na paralisia cerebral espástica é a adução e a rotação interna do ombro, a flexão do cotovelo, a pronação de antebraço e a flexão do punho e dos dedos ${ }^{4}$.

A deformidade do ombro em adução e rotação interna deve-se à espasticidade e ao encurtamento dos músculos peitoral maior e subescapular, limitando a abdução e a rotação externa. A flexão do cotovelo varia de acordo com a gravidade da lesão cerebral, e a ação do bíceps e do braquial é a causa primária da flexão. Já o padrão em flexão do punho e dos dedos deve-se à espasticidade e ao encurtamento da massa flexora pronadora ${ }^{5}$. Deve-se, ainda, considerar a possível presença de instabilidade escapular, que pode contribuir para o desalinhamento articular.

Exercício 1 (abdução do ombro): com o paciente em decúbito dorsal no tablado, com o ombro fletido a noventa graus, o terapeuta com uma das mãos segura distalmente o úmero, com a outra mão estabiliza a borda axilar da escápula, movendo o ombro em abdução completa, alongando os adutores ${ }^{14}$.

Exercício 2 (rotação externa do ombro): com o paciente em decúbito dorsal no tablado, com o ombro em abdução e o cotovelo fletido em noventa graus, o terapeuta segura distalmente o antebraço com uma das mãos e estabiliza o cotovelo com a outra. A escápula estará estabilizada pelo tablado. Rodar externamente o ombro do paciente, movendo seu antebraço para perto do tablado e alongando os rotadores internos ${ }^{14}$.

Exercício 3 (extensão do cotovelo): estando o paciente posicionado em decúbito dorsal, o terapeuta segura distalmente com uma mão o antebraço e com a outra mão estabiliza a escápula e a face anterior do úmero proximalmente, estendendo o cotovelo ao máximo para alongar os flexores de cotovelo (executar esse alongamento com o antebraço em supinação).

Exercício 4 (transferência de peso em MMSS): o paciente deve posicionar-se em decúbito ventral em uma bola terapêutica ou feijão, com as mãos apoiadas no chão com extensão de cotovelos, punhos e dedos, transferindo o peso para os membros superiores (MMSS).

Exercício 5 (posição de gato - transferindo peso em MMSS): com o paciente na posição de gato (se for necessário o terapeuta dá suporte para posição), realizar a transferência de peso em membros superiores, melhorando assim a estabilidade da cintura escapular e a força de MMSS. O terapeuta deve manter a extensão de cotovelos do paciente, prevenindo a ocorrência de hiperextensão.

Exercício 6 (função): com o paciente sentado em um banquinho, com os pés apoiados, estimular o paciente a pegar os objetos colocados nas diagonais.

\section{Discussão e conclusão}

Esta proposta de tratamento tem como objetivo a correção ou a prevenção das deformidades musculoesqueléticas nas crianças com paralisia cerebral espástica tetraparética, diparética ou hemiparética.

O estudo tem por finalidade mostrar melhor visão do tratamento, fazendo com que as crianças, com paralisia cerebral, usem o máximo de suas atividades motoras e desempenhem as tarefas cotidianas, de modo mais funcional e independente, prevenindo as 
anormalidades de postura e as deformidades articulares decorrentes do déficit motor.

$\mathrm{O}$ tratamento fisioterapêutico nas alterações musculoesqueléticas em crianças com paralisia cerebral é muito abrangente, pois as causas dessas alterações podem ser diversas (espasticidade, encurtamento muscular, instabilidade articular, fraqueza muscular). Nas crianças tetraparéticas, diparéticas e hemiparéticas, o tratamento também será diferenciado, devendo-se sempre considerar a avaliação e o comportamento para cada criança em particular.

Assim, trazemos uma proposta de conduta a ser realizada nos pacientes com paralisia cerebral e alterações ortopédicas, possibilitando correções ou reduções das dificuldades funcionais que decorrem do comprometimento articular.

\section{SUMMARY}

Physiotherapeutic treatment proposal to children with spastic cerebral palsy, emphasising musculoskeletal disorders

Cerebral palsy or non evolutive chronic encephalopathy is used to desingnate a group of sensorial and motor neuron disorders resulted from cerebral lesions within the earlier stages of growth. These disorders are characterized by the lack of control upon movement, also by adaptive modification of the muscle length and, in some cases, they can even result in orthopedic deformities. This article aims to elaborate a physiotherapeutic treatment proposal which emphasizes the broach of the main musculoskeletal disorders from children with quadriplegic, diplegic and hemiplegic spastic cerebral palsy. The results of this research show exercises used to increase mobility as well as joint stability, its strength and functional training in order to obtain greater independency and enhance the life quality of those children.

\section{Keywords}

Cerebral palsy, physiotherapy treatment, orthopedic deformities.

\section{Referências}

1. Alcantra P, Marcondes E. Pediatria básica. 4 ed. São Paulo, Sarvier, 1974, v. 2, 1421-2.

2. Apley G, Solomon L. Ortopedia e fraturas em medicina e reabilitação. 6 ed. São Paulo, Atheneu, 1998, p. 296.
3. Behrman RM, Kliegman R, Arvin A. Tratado de pediatria. 15 ed. Rio de Janeiro, Guanabara Koogan, 1997, v. 2, pp. 2223-4.

4. Bruschini $S$ et al. Ortopedia pediátrica. 2 ed. São Paulo, Atheneu, 1998, pp. 172-258.

5. Bruschini $S$ et al. Ortopedia pediátrica. São Paulo, Atheneu, 1993, pp. 98-125.

6. Burns YR, MacDonalds J. Fisioterapia e crescimento na infância. São Paulo, Santos Livraria, 1999, pp. 274-6.

7. Camanho GL et al. Patologia do joelho. São Paulo, Sarvier, 1996, pp. 302-5.

8. Campbell. Cirurgia ortopédica de Campbell. 8 ed. São Paulo, Manole, 1996.

9. Dimeglio A. Ortopedia pediátrica. 1 ed. São Paulo, Santos Livraria, 1990, pp. 372-99.

10. Ferrareto I, Souza AMC. Como tratamos a paralisia cerebral: reabilitação. São Paulo, AACD escritório editorial, 1997, pp. 5-19.

11. Ferrareto I, Souza AMC. Paralisia cerebral: aspectos práticos. São Paulo, ABPC, 1998.

12. Hebert $S$, Xavier R, Pardini A, Barros TEP. Ortopedia e traumatologia: princípios e prática. 2 ed. Porto Alegre, Artmed, 1998, pp. 238-92.

13. Keren M, Livanelioglua A, Topcu M. Effects of Johnstone pressure splints combined with neurodevelopmental terapy on spasticity and culaneus sensory inputs in spastc cerebral palsy. Dev Med Child Neurol, 43:307-12, 2001.

14. Kisner C, Colby LA. Exercícios terapêuticos: fundamentos e técnicas. 3 ed. São Paulo, Manole, 1998.

15. Koman A, Brashear A, Rosenfeld S, Chambers $H$, Russman B, Rang M, Root L, Ferrari E, Prous JGY, Smith B, Pharmd C, Walcott J, Molloy P. Butuliun toxin type a neuromuscular blockade in the treatment of equinus foot deformith in cerebral palsy: a multicenter, open-lavel clinical trial. Pediatrics, 108:1062-71, 2001.

16. Kudo AM, Marcondes E, Lins L, Moriyama LT, Guimarães ML, Juliana RC, Pierri AS. Fisioterapia, fonoaudiologia e terapia ocupacional em pediatria. 2 ed. São Paulo, Sarvier, 1997, pp. 36-45.

17. Lepage C, Noreall L, Bernard P. Association between characteristics of locomotion and accomplishment of life habits in children with cerebral palsy. Phys Ther, 78: 45869, 1998.

18. Marcondes E et al. Pediatria básica. 8 ed. São Paulo, Sarvier, 1991, v. 2, pp. 1770-1.

19. Petersen MC, Kube DA, Palmer FB. Classification of developmental delays. Sem Ped Neural, 5:2-14, 1998.

20. Rolf IP. Rolfing: a integração das estruturas humanas. 2 ed. São Paulo, Martins Fontes, 1999, pp. 42-3.

21. Shepherd RB. Fisioterapia em pediatria. 3 ed. São Paulo, Livraria Santos, 1998, pp. 224-77.

22. Tachdjan MO. Ortopedia pediátrica. 2 ed. São Paulo, Manole, 1995, v. 3, pp. 1622-712.

23. Tribastone F. Tratado de exercícios corretivos aplicados à reeducação motora postural. São Paulo, Manole, 2001.

\footnotetext{
Endereço para correspondência:

Rua Arino Cargnin, 95 - Termas do Gravatal CEP 88735-000 - Gravatal, SC
} 